\title{
Factors favoring stent-graft collapse after thoracic endovascular aortic repair
}

\author{
Ludovic Canaud, MD, ${ }^{\mathrm{a}}$ Pierre Alric, MD, PhD, ${ }^{\mathrm{a}}$ Pascal Desgranges, MD, PhD, ${ }^{\mathrm{b}}$ Jean Marzelle, MD, \\ Charles Marty-Ané, MD, PhD, ${ }^{\mathrm{a}}$ and Jean-Pierre Becquemin, $\mathrm{MD}^{\mathrm{b}}$
}

Objective: Our objective was to assess potential causative factors of stent-graft collapse after thoracic endovascular aortic repair.

\begin{abstract}
Methods: We retrospectively reviewed clinical data and preoperative and postoperative computed tomographic scans of patients with thoracic stent-graft collapse in 2 French departments of vascular surgery. Aortic arch angulation, length of the lack of device wall apposition, proximal aortic diameter, and percentage of oversizing were assessed.

Results: We report 4 cases of stent-graft collapse among 285 patients treated by thoracic endovascular aortic repair. All 4 patients were treated with the TAG stent graft. Only one of the patients had a symptomatic collapse: he was treated by stent-graft explantation and open repair. Endovascular management was performed in 3 of the 4 patients. None of the patients died. Lack of device wall apposition and acute aortic arch angle (range $92^{\circ}-118^{\circ}$ ) were observed in all 4 patients. Oversizing over $20 \%$ was observed in 3 patients.
\end{abstract}

Conclusion: This stent-graft-related complication seems related to poor apposition of the stent grafts in the highly angulated aortic arch. Excessive stent-graft oversizing could be an additional causative factor. Accurate assessment of aortic arch anatomic features, as well as the choice and sizing of the device, may prevent this complication. (J Thorac Cardiovasc Surg 2010;139:1153-7)

Stent-graft placement is advocated as a safe and effective treatment for various diseases of the descending aorta and, recently, of challenging anatomic regions such as the aortic arch. ${ }^{1}$

A significant number of complications have been reported and, recently, cases of stent-graft collapse have been identified with a high risk of complications and death. Several factors may influence the results of thoracic endovascular aortic repair (TEVAR), including the proximal aortic landing zone (length, angulation, and morphologic structure of the aortic wall) and the choice of device.

Anatomic challenges are still the most important factors of early and late stent-graft failure.

We report on 4 cases of stent-graft collapse after TEVAR in patients from 2 French institutions. We assessed anatomic features of the aortic arch and sizing of stent grafts involved in stent-graft collapse.

\section{METHOD}

This study was approved by the institutional review board. Between 1997 and 2008, 285 patients had TEVAR

\footnotetext{
From the Department of Vascular and Thoracic Surgery, ${ }^{\mathrm{a}}$ Arnaud de Villeneuve Hospital, Montpellier, France, and the Department of Vascular Surgery, ${ }^{\mathrm{b}}$ Henri Mondor Hospital, Créteil, France.

Disclosures: None.

Received for publication May 2, 2009; revisions received June 3, 2009; accepted for publication June 20, 2009; available ahead of print July 30, 2009.

Address for reprints: Ludovic Canaud, MD, Service de Chirurgie Vasculaire et Thoracique, Hôpital A deVilleneuve, 191 av Doyen Gaston Giraud 34090, Montpellier, France (E-mail: ludoviccanaud@hotmail.com).

$0022-5223 / \$ 36.00$

Copyright (c) 2010 by The American Association for Thoracic Surgery doi:10.1016/j.jtcvs.2009.06.017
}

in 2 French university hospital departments of vascular surgery (A de Villeneuve Hospital, Montpellier, France; Henri Mondor Hospital, Créteil, France). In 4 (1.4\%) of them, stent-graft collapse was identified.

We studied clinical data, stent-graft sizing, and preoperative or postoperative computed tomographic (CT) scans of patients identified with stent-graft collapse (Figure 1). Measurements included aortic arch angulation, proximal aortic diameter, and length between the proximal edge of the stent graft, if not in apposition to the aortic wall and the inner curve of the aortic arch (intraluminal lip length). All the measurements of diameters and angulations were performed with a central lumen line (GE Advantage 4.0 workstation; General Electric, Waukesha, Wis).

\section{RESULTS}

All relevant anatomic and clinical data are summarized in Table 1. All 4 patients were treated with a second-generation Gore TAG stent graft (W. L. Gore \& Associates, Inc, Evry, France). Three of our patients were treated outside Gore's instructions for use (minimum required aortic diameter of 23 $\mathrm{mm}$ ), and furthermore the device was used off-label in all cases (chronic type B dissection, traumatic transection of the thoracic aorta). One patient had an elective endovascular procedure (patient 3 ) and 3 patients had an emergency procedure.

In all cases, stent grafts were successfully deployed in the intended position. Completion angiogram did not show any endoleak. All patients underwent a postoperative CT scan without evidence of stent-graft collapse. However, in all patients poor apposition of the stent graft along the inner curve 


\section{Abbreviations and Acronyms}

$\mathrm{CT}=$ computed tomography

TEVAR $=$ thoracic endovascular aortic repair

of the aortic arch was noted (Figure 2) with the stent graft protruding into the lumen of the aorta (mean intraluminal lip length: $9.2 \mathrm{~mm}$; range $8-12 \mathrm{~mm}$ ). Furthermore, a severely angulated proximal aortic neck was always observed: mean angle of $104.5^{\circ}$ (range $92^{\circ}-108^{\circ}$ ). Among the remaining patients $(\mathrm{n}=281)$ who underwent TEVAR but who did not experienced thoracic stent-graft collapse, a lack of device wall apposition was observed in $43(15.3 \%)$ patients and oversizing over $20 \%$ in $37(13.1 \%)$.

In patient 3, extra-anatomic revascularization of the left common carotid artery associated with revascularization of the left subclavian artery was required to provide a sufficient proximal landing zone. A first TAG stent graft $(40-150 \mathrm{~mm})$ was inserted at the level of the aortic arch, but incomplete coverage of the target area required complementary deployment of a second TAG stent graft (40-100 mm), overlapping the first stent graft by a 2-stent long overlap.

The mean interval from thoracic stent-graft implantation to collapse was \pm 8.9 days (range, $16-37$ days). In patient 1 , on the 30th postoperative day, stent-graft collapse was revealed by a pseudocoarctation syndrome leading to functional renal failure. Open explantation and repair by a left thoracotomy was successfully performed with partial left heart femoral artery-femoral vein cardiopulmonary bypass (Figure 3). The postoperative course was uneventful and the patient was discharged on day 10 .

Three patients were asymptomatic and the collapsed stent grafts were identified on routine postoperative CT scan. In patient 3, the collapsed stent graft was the second overlapping stent graft and was associated with a type III endoleak. These 3 patients underwent endovascular treatment of their stent-graft collapse. Patients 2 and 3 underwent placement of a second stent graft (patient 2: Valiant Medtronic Vascular; Santa Rosa, Calif; patient 3: Zenith TX; Cook Inc, Bloomington, Ind) within the first to cause re-expansion. Patient 4 underwent deployment of a large balloon expandable stent in the proximal stent graft (Palmaz stent; Cordis, Cordis Endovascular, Miami Lakes, Fla) that successfully re-expanded the collapsed stent grafts.

Mean follow-up was $23 \pm 10.4$ months (range, 12-37 months). In all cases, the postoperative course was uneventful. Repeated CT scans confirmed absence of endoleak and fully expanded proximal stent graft in all patients.

\section{DISCUSSION}

Endovascular management has emerged during the past decade as a valuable treatment modality for thoracic aortic

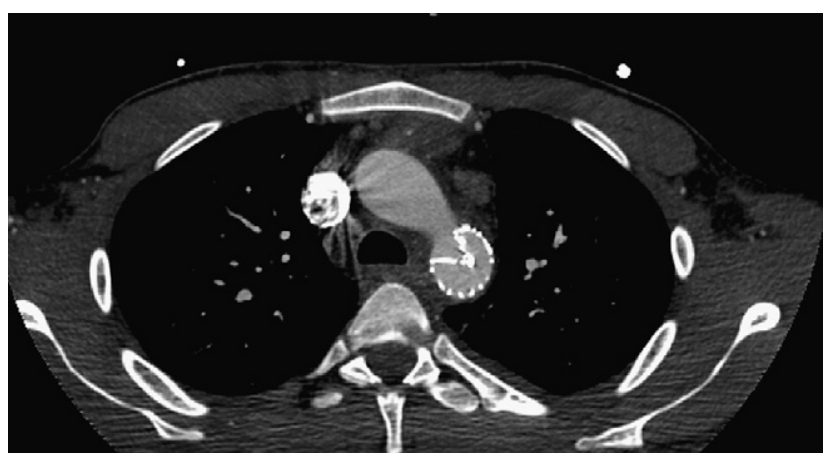

FIGURE 1. Stent-graft collapse after thoracic endovascular aortic repair of a traumatic aortic disruption (patient 1).

diseases. However, a significant number of complications have occurred. Since the first report by Melissano and associates, ${ }^{2}$ more recent isolated reports have identified patients with stent-graft collapse. We reviewed the literature ${ }^{2-14}$ (Table 2) and found 29 cases of thoracic stent-graft collapse. Among these patients, the overall mortality rate of this potentially devastating complication was $6.8 \%$. Cases have been observed with the following brands: TAG (Gore), Zenith (Cook), and Endofit (LeMaitre Vascular, Burlington, Mass).

Collapses occurred when the stent grafts were inserted in angulated aortic necks (aortic isthmus), frequent in young patients, who are often involved in trauma. This complication rarely occurs in the longer and wider aortas associated with aneurysmal disease. However, we report on a case of collapsed stent graft implanted in a chronic type B dissecting thoracic aneurysm (patient 4). In a multi-institutional retrospective analysis, Muhs and colleagues ${ }^{11}$ collected CT scans of 6 patients who had confirmed TAG stent-graft collapse. They reported several factors that may influence this complication: lack of apposition of the stent graft to the aortic wall, also called the "bird's beak" deformity ${ }^{15}$; acute aortic arch angulation, distal aortic diameter and minimum intragraft aortic diameter (aortic diameter perpendicular to the center lumen line at the intragraft landing zone), small diameter aortas, and high percentage of oversizing. Distal aortic diameter and minimum intragraft aortic diameter predicted collapse. Other variables may also influence this complication but were not found significant owing to potential type II statistical errors related to small the sample size in this report.

In our patients, potential anatomic risk factors increasing the probability of stent-graft collapse were acute aortic arch angulation and poor apposition of the stent graft to the inner curve of the aortic arch. In cases of severely angulated proximal aortic neck, stent grafts are unable to conform to the inner curvature of the arch. Stent grafts protrude into the lumen of the aortic arch. This lack of device wall apposition exposes the device to repetitive pullout strengths that can lead to stent fracture and/or collapse. 
TABLE 1. Summary of our reported stent-graft collapses

\begin{tabular}{|c|c|c|c|c|c|c|c|c|}
\hline Patient & $\begin{array}{c}\text { Indication for } \\
\text { endovascular } \\
\text { repair } \\
\end{array}$ & Symptoms & $\begin{array}{c}\text { Proximal } \\
\text { aortic } \\
\text { diameter }(\mathbf{m m}) \\
\end{array}$ & $\begin{array}{c}\text { Oversizing } \\
(\%) \\
\end{array}$ & $\begin{array}{c}\text { Aortic } \\
\operatorname{arch} \\
\text { angulation }\left(^{\circ}\right)\end{array}$ & $\begin{array}{c}\text { Intraluminal } \\
\text { lip length } \\
(\mathrm{mm})\end{array}$ & CT scan & Treatment \\
\hline 1 & $\begin{array}{l}\text { Traumatic aortic } \\
\text { rupture }\end{array}$ & $\begin{array}{l}\text { Pseudocoarctation } \\
\text { syndrome }\end{array}$ & 20 & 30 & 100 & 8 & $\begin{array}{l}\text { Collapsed stent } \\
\text { graft }\end{array}$ & $\begin{array}{c}\text { Open repair and } \\
\text { explantation }\end{array}$ \\
\hline 2 & $\begin{array}{l}\text { Traumatic aortic } \\
\text { rupture }\end{array}$ & None & 20.5 & 26.8 & 108 & 9 & $\begin{array}{l}\text { Collapsed stent } \\
\text { graft }\end{array}$ & Stent graft (Valiant) \\
\hline 3 & $\begin{array}{l}\text { Chronic type B } \\
\text { dissecting } \\
\text { thoracic } \\
\text { aneurysm }\end{array}$ & None & 32 & 18.7 & 118 & 8 & $\begin{array}{l}\text { Collapse of the } 2 \mathrm{nd} \\
\text { overlapping stent } \\
\text { graft and type III } \\
\text { endoleak }\end{array}$ & $\begin{array}{l}\text { Stent graft (Zenith } \\
\quad \text { TX) }\end{array}$ \\
\hline 4 & $\begin{array}{l}\text { Complicated acute } \\
\text { type B dissection }\end{array}$ & None & 21 & 23.5 & 92 & 12 & $\begin{array}{l}\text { Collapsed stent } \\
\text { graft }\end{array}$ & Giant Palmaz stent \\
\hline
\end{tabular}

In a previous experimental study, we ${ }^{16}$ assessed fixation of 4 commercially available thoracic stent grafts according to aortic arch angulation and to oversizing. The major features in stent-graft design providing a secure proximal anchorage seem to be the radial force and the presence of a proximal open stent segment. As a consequence, in cases of severe aortic arch angulation, a stent graft with a more efficient proximal anchorage system and a more important radial force seems to be advocated to avoid poor apposition of the proximal edge of the stent graft.

In our patients, excessive oversizing was not systematically observed. Three of our patients were treated outside Gore 's instructions for use (minimum required aortic diameter of $23 \mathrm{~mm}$ ). Currently available stent grafts are too large and do not allow moderate oversizing. Owing to aortic compliance, aortic diameters vary during cardiac cycles. Aortic diameter variations between systole and diastole can reach $17.8 \%$ in specific segments. Thus, preoperative sizing of stent-graft diameters with static CT scans may lead to an excessive oversizing. ${ }^{17}$ Three of the 4 patients were treated in an emergency setting, and for logistic reasons the oversized stent grafts were the only type available. Prompt availability of adequately sized grafts could help to overcome the problem. Oversizing is not the only reason for stent-graft collapse. One of our patients, as in a series reported by Steinbauer and associates, ${ }^{7}$ had a collapse despite a lack of excessive oversizing.

Our 4 patients were treated with a TAG stent graft (Gore). Most reported cases of stent-graft collapse involve the TAG device. Many factors may explain this trend: (1) the TAG stent graft is widely used in the United States (until June 2008, the TAG device was the only endovascular stent graft approved by the Food and Drug Administration); (2) as a severely oversized stent graft may increase the probability of stent-graft collapse, the minimum diameter of the TAG device is $26 \mathrm{~mm}$ as compared with the small $(\leq 20 \mathrm{~mm})$ aortic diameters seen in young patients, especially in case of traumatic transection of the aorta.
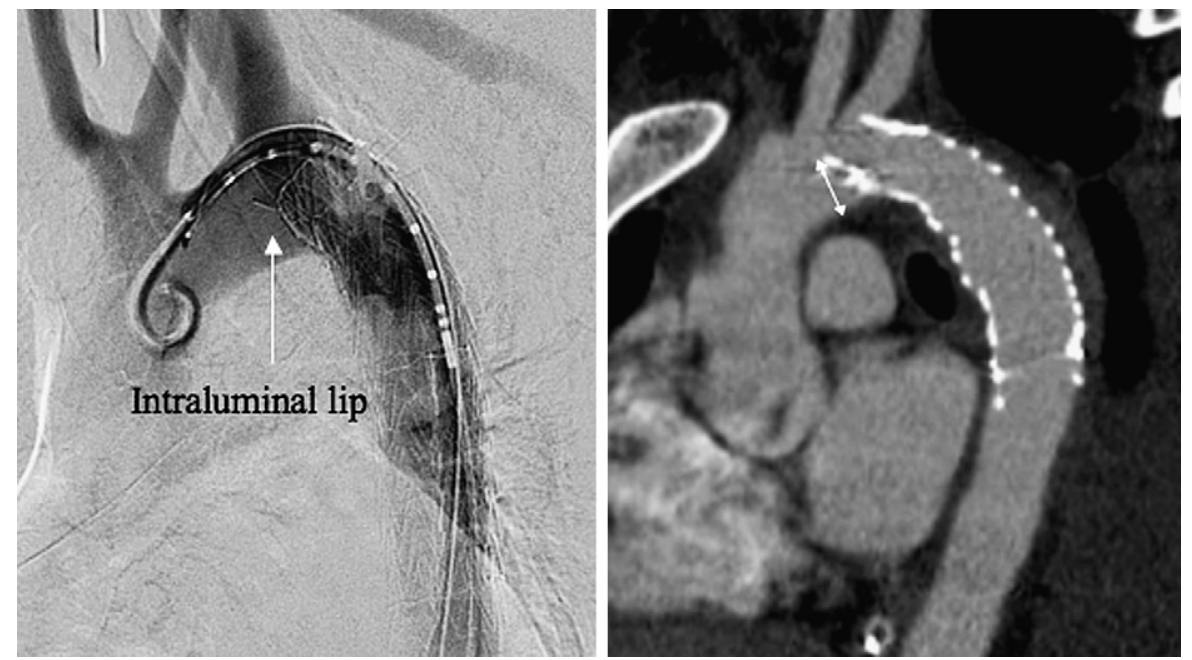

FIGURE 2. CT scan and angiography demonstrating a poor apposition of the stent graft along the inner curve of the aortic arch with the stent graft protruding into the lumen of the aorta. 


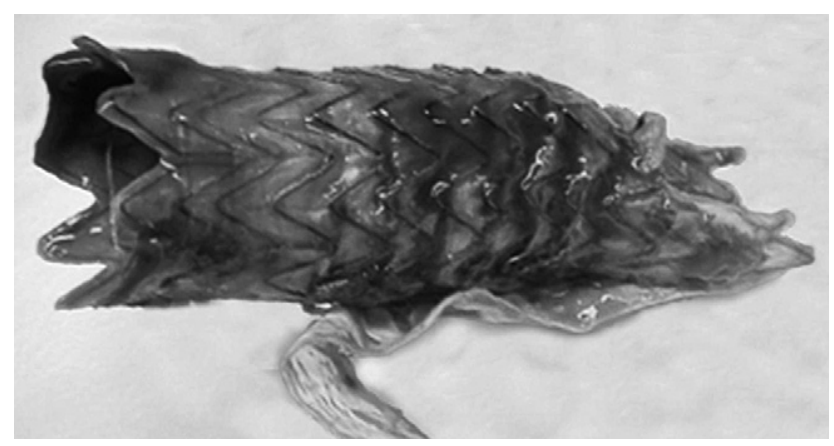

FIGURE 3. Collapsed stent graft after surgical explantation.

The critical period of highest risk of collapse seems to be within the first month after implantation. However, as demonstrated in a recent report, ${ }^{10}$ thoracic stent-graft collapse can occur in a delayed fashion (11 months after TEVAR). The potential for this deferred complication underscores the need for prolonged follow-up CT scans in these patients.

In the presence of one of the anatomic factors (aortic arch angulation, small diameter aortas), caution is recommended in planning a treatment strategy and other options should be discussed to avoid thoracic stent-graft collapse. In elective cases, open surgery should be considered. When endovascular repair is considered, the choice of the device is critical. A device with an important radial force and the presence of a proximal open stent segment should be preferred. Wellons and coworkers ${ }^{18}$ advocate the use of aortic extension cuffs because of their appropriate diameter. However, multiple cuffs may be necessary to obtain an adequate seal and a sufficient length of the stent graft. This induces a significant risk for disconnection of the multiple aortic cuffs. Riesenman and associates ${ }^{19}$ reported a case of endovascular exclusion of a thoracic aortic disruption using an abdominal aortic stent graft in the iliac limb. The repair was complicated by stent-graft collapse and the development of a functional co- arctation. Kölbel and colleagues ${ }^{20}$ described a technique of in situ bending of a thoracic stent graft to improve thoracic stent-graft apposition. When poor apposition of the proximal edge of the stent graft to the inner curve of the aorta is achieved, repeated follow-up CT scans should be performed to identify asymptomatic collapsed stent graft. The use of adjunctive technology to improve conformity of thoracic stent grafts in the arch and fixation of the proximal stent graft should be considered. Stehr and associates ${ }^{21}$ recommend either deploying another proximal stent graft or achieving fixation of the proximal stent graft by a balloon-expandable Palmaz stent.

Several therapeutic options can be proposed: The stent graft can either be removed via an open thoracotomy or be re-expanded by an endoluminal approach. Most reported cases have been treated by the implantation of an XL Palmaz stent (Cordis) or by the implantation of another endovascular graft within the collapsed stent graft. Open stent-graft removal and aortic repair through a left thoracotomy, as performed in patient 1 , is another option. Open repair should be considered in cases of severely collapsed stent graft and/or deemed at high risk of coverage of supra-aortic trunks owing to a severely angulated aortic arch, as in patient 1 .

\section{CONCLUSION}

In our patients, stent-graft collapse after TEVAR seems to be related to poor apposition of the stent grafts in a highly angulated aortic arch and/or excessive stent-graft oversizing. In planning a treatment strategy, assessment of aortic arch anatomy and appropriate choice of the device may prevent such a complication. In cases of poor apposition of the proximal edge of the stent graft to the inner curve of the aorta, close CT scan follow-up should be performed. Furthermore, the use of adjunctive technologies to enhance fixation of the proximal stent graft should be considered.

TABLE 2. Thoracic stent-graft collapse: Review of reported cases

\begin{tabular}{|c|c|c|c|c|c|}
\hline First author & Year & No. & Mortality & Endograft & Symptoms \\
\hline Melissano $^{2}$ & 2004 & 1 & 0 & Endofit (1) & 0 \\
\hline $\mathrm{Idu}^{3}$ & 2005 & 1 & 0 & TAG (1) & $100 \%(1)$ \\
\hline Mestres $^{4}$ & 2006 & 1 & 0 & TAG (1) & $100 \%$ \\
\hline Hoornweg $^{5}$ & 2006 & 1 & 0 & TAG (1) & 0 \\
\hline Tehrani $^{6}$ & 2006 & 1 & 0 & TAG (1) & NA \\
\hline Steinbauer $^{7}$ & 2006 & 2 & 0 & TAG (2) & 0 \\
\hline Hinchliffe $^{8}$ & 2007 & 7 & $28.6 \%(2)$ & TAG (6) Zenith (1) & $42.8 \%(3)$ \\
\hline $\mathrm{Go}^{9}$ & 2007 & 1 & 0 & TAG $(1)$ & $100 \%(1)$ \\
\hline Rodd $^{10}$ & 2007 & 3 & 0 & TAG (3) & $66.7 \%(2)$ \\
\hline Muhs $^{11}$ & 2007 & 6 & 0 & TAG (6) & NA \\
\hline Neschis $^{12}$ & 2007 & 1 & 0 & TAG (1) & 0 \\
\hline Leung $^{13}$ & 2008 & 3 & 0 & TAG (3) & 0 \\
\hline Canaud $^{14}$ & 2008 & 1 & 0 & TAG (1) & 1 \\
\hline Overall & & 29 & $6.8 \%(2)$ & TAG (27)Zenith (1)Endofit (1) & $31 \%(9)$ \\
\hline
\end{tabular}

NA, Not available. TAG, W. L. Gore \& Associates, Inc, Evry, France; Zenith, Cook Inc, Bloomington, Ind; and Endofit, LeMaitre Vascular, Burlington, Mass. 


\section{References}

1. Ishimaru S. Endografting of the aortic arch. J Endovasc Ther. 2004;11:62-71.

2. Melissano G, Tshomba Y, Civilini E, Chiesa R. Disappointing results with a new commercially available thoracic endograft. J Vasc Surg. 2004;39:124-30.

3. Idu MM, Reekers JA, Balm R, Ponsen KJ, de Mol BA, Legemate DA. Collapse of a stent-graft following treatment of a traumatic thoracic aortic rupture. J Endovasc Ther. 2005; 12:503-7.

4. Mestres G, Maeso J, Valentin F, Matas M. Symptomatic collapse of a thoracic aorta 246 endoprosthesis. J Vasc Surg. 2006;43:1270-3.

5. Hoornweg LL, Dinkelman MK, Goslings JC, Reekers JA, Verhagen HJ, Verhoeven EL, et al. Endovascular management of traumatic ruptures of the thoracic aorta: a retrospective multicenter analysis of 28 cases in The Netherlands. J Vasc Surg. 2006;43:1096-102.

6. Tehrani HY, Peterson BG, Katariya K, Morasch MD, Stevens R, DiLuozzo G, et al. Endovascular repair of thoracic aortic tears. Ann Thorac Surg. 2006;82: 873-7.

7. Steinbauer MG, Stehr A, Pfister K, Herold T, Zorger N, Töpel I, et al. Endovascular repair of proximal endograft collapse after treatment for thoracic aortic disease. J Vasc Surg. 2006;43:609-12.

8. Hinchliffe RJ, Krasznai A, Schultzekool L, Blankensteijn JD, Falkenberg M, Lönn L, et al. Observations on the failure of stent-grafts in the aortic arch. Eur J Vasc Endovasc Surg. 2007;34:451-6.

9. Go MR, Barbato JE, Dillavou ED, Gupta N, Rhee RY, Makaroun MS, et al. Thoracic endovascular aortic repair for traumatic aortic transection. J Vasc Surg. 2007;46:928-33.

10. Rodd CD, Desigan S, Hamady MS, Gibbs RG, Jenkins MP. Salvage options after stent collapse in the thoracic aorta. J Vasc Surg. 2007;46:780-5.

11. Muhs BE, Balm R, White GH, Verhagen HJ. Anatomic factors associated with acute endograft collapse after Gore TAG treatment of thoracic aortic dissection or traumatic rupture. J Vasc Surg. 2007;45:655-61.
12. Neschis DG, Moaine S, Gutta R, Charles K, Scalea TM, Flinn WR, et al. Twenty consecutive cases of endograft repair of traumatic aortic disruption: lessons learned. J Vasc Surg. 2007;45:487-92.

13. Leung D, Davis I, Katlaps G, Tisnado J, Sydnor M, Komorowski D, et al. Treatment of infolding related to the Gore TAG thoracic endoprosthesis. J Vasc Interv Radiol. 2008;19:600-5.

14. Canaud L, Alric P, Branchereau P, Marty-Ané C, Berthet JP. Lessons learned from midterm follow-up of endovascular repair for traumatic rupture of the aortic isthmus. J Vasc Surg. 2008;47:733-8.

15. Svensson LG, Kouchoukos NT, Miller DC, Bavaria JE, Coselli JS, Curi MA, et al Society of Thoracic Surgeons Endovascular Surgery Task Force. Expert consensus document on the treatment of descending thoracic aortic disease using endovascular stent-grafts. Ann Thorac Surg. 2008;85:1-41.

16. Canaud L, Alric P, Laurent M, Baum TP, Branchereau P, Marty-Ané CH, et al. Proximal fixation of thoracic stent-grafts as a function of oversizing and increasing aortic arch angulation in human cadaveric aortas. J Endovasc Ther. 2008;15:326-34.

17. Muhs BE, Vincken KL, van Prehn J, Verhoeven EL, Prokop M, Moll FL, et al Dynamic cine-CT angiography for the evaluation of the thoracic aorta; insight in dynamic changes with implications for thoracic endograft treatment. Eur $J$ Vasc Endovasc Surg. 2006;32:532-6.

18. Wellons ED, Milner R, Solis M, Levitt A, Rosenthal D. Stent-graft repair of traumatic thoracic aortic disruptions. J Vasc Surg. 2004;40:1095-100.

19. Riesenman PJ, Farber MA, Fulton JJ. Endograft malapposition in the distal aortic arch resulting in functional coarctation. Vasc Endovasc Surg. 2008;41:533-6.

20. Kölbel T, Lee T, Ivancev K, Resch TA, Sonesson B, Malina M. In situ bending of a thoracic stent-graft: a proposed novel technique to improve thoracic endograft seal. J Endovasc Ther. 2008;15:62-6.

21. Stehr A, Steinbauer M, Pfister K, Töpel I, Herold T, Zorger N, et al. Diagnosis and endovascular treatment of proximal endograft instability after thoracic endografting. Zentralbl Chir. 2007;132:211-5. 